\title{
LA RESTITUCIÓN DE TIERRAS EN COLOMBIA EXPECTATIVAS Y RETOS*
}

\section{Claudia Margarita Martínez Sanabria** Andrea Carolina Pérez Forero****}

Fecha de recibido: 30 de abril de 2012

Fecha de aprobación: 13 de junio de 2012

Artículo resultado de investigación

\begin{abstract}
Resumen
Se pretende hacer un estudio de la obligación a cargo del Estado Colombiano de restituir las tierras que les han sido arrebatadas a los desplazados-víctimas del conflicto armado, como parte de la obligación de reparación integral.

Dentro de éste contexto se analizará el problema del desplazamiento forzado interno en Colombia a partir de sus antecedentes e identificación de los derechos de los desplazados y la regulación y jurisprudencia que se ha expedido en la materia. Así mismo, se analizará la normatividad que regula la reparación integral a las víctimas y específicamente la restitución de tierras, contenida en la Ley 1448 de 2011, con el fin de identificar sus principales componentes y las expectativas y retos que conlleva su aplicación práctica, para que no sea simplemente un derecho consagrado en la Ley como mera ilusión de las víctimas, sino una realidad que materialice la justicia.
\end{abstract}

\section{Palabras clave}

Desplazamiento forzado, restitución de tierras, conflicto armado, víctimas, reparación integral.

\section{LAND RESTITUTION IN COLOMBIA EXPECTATIONS AND CHALLENGES}

\begin{abstract}
Abstrac
On this paper tries is to do a study of the obligation at the expense of the Colombian State to return the lands that there have been snatched to displaced victims of the armed conflict, as part of the obligation of integral repair.
\end{abstract}

* El presente artículo es resultado de la investigación "La restitución de tierras como eje fundamental de la reparación integral a los desplazados víctimas del conflicto armado en Colombia" del Grupo de Derecho Público reconocido por COLCIENCIAS en Categoría B, del Centro de Investigaciones Jurídicas, Políticas y Sociales de la Facultad de Derecho de la Universidad Militar Nueva Granada. Investigadora principal Dra. Claudia Margarita Martínez Sanabria y coinvestigadora Dra. Andrea Carolina Pérez Forero, con la participación de los estudiantes de pregrado de derecho, Miguel Ángel Laborde Meek, Sandra Carolina Martínez Sanabria, Jennifer Gamboa Rodríguez y Alexandra Charry Salas.

* Abogada Magna Cum Laude de la Universidad Militar Nueva Granada, especialista en Docencia Universitaria, Magister en Derecho Administrativo de la Universidad Militar Nueva Granada. Docente de planta de tiempo completo de la Facultad de Derecho de la Universidad Militar Nueva. Correo electrónico: claudia.martinez@unimilitar.edu.co

**** Abogada Magna Cum Laude de la Universidad Militar Nueva Granada, cursando especialización en Derecho Contractual y Derecho Comercial en la Universidad del Rosario, Docente de planta de tiempo completo de la Facultad de Derecho de la Universidad Militar Nueva. Correo electrónico: andrea.perez@unimilitar.edu.co 
Within this context we will analyze the problem of internal displacement in Colombia, their history and identification of their rights and the regulation and jurisprudence that has been issued on the subject. In addition, we will analyze the regulations governing to victims reparation and the restitution of land specifically contained in Law 1448 promulgated on 2011 , to identify its main components and the expectations and challenges associated with practical application to do it not as a simply as a right enshrined in the law as a mere illusion of the victims, but a reality which does justice.

\title{
Key words
}

Forced displacement, Return of land, armed conflict, victims, reparation.

\section{RESTITUIÇÃO DE TERRAS NA COLÔMBIA EXPECTATIVAS E DESAFIOS}

\begin{abstract}
Resumo
No presente trabalho tenta é fazer um estudo sobre a obrigação à custa do Estado colombiano para devolver as terras que não foram arrancadas às vítimas deslocados do conflito armado, como parte da obrigação de reparação integrante.

Dentro deste contexto, vamos analisar o problema do deslocamento interno na Colômbia, de sua história e identificação dos seus direitos e à regulamentação e jurisprudência que tenha sido emitida sobre o assunto. Além disso, vamos analisar os regulamentos que regem a vítimas e reparação a restituição das terras especificamente previstas na Lei 1448, promulgada em 2011, para identificar seus principais componentes e as expectativas e os desafios associados com a aplicação prática de fazer não é simplesmente como um direito consagrado na lei como mera ilusão das vítimas, mas uma realidade que faz justiça.
\end{abstract}

\section{Palavras-chave}

O deslocamento forçado, O Retorno de terra, conflitos armados, as vítimas, a reparação.

\section{INTRODUCCIÓN}

Uno de los fines del Estado es garantizar la seguridad nacional, procurando la dignificación de las personas y gestionando la resolución de los conflictos para mantener relaciones pacíficas entre los asociados. Igualmente es su deber estar atento y vigilar las situaciones jurídicas y sociales en las que se encuentran sus habitantes para propender por la protección de su vida, honra y bienes, en los términos consagrados en el Artículo $2^{\circ}$ de la Constitución Nacional.

En relación con lo anterior, nace para el Estado la obligación de impedir el desplazamiento o en consecuencia adoptar medidas efectivas para la protección de los derechos de los desplazados, cuya condición los hace más vulnerables dentro del contexto del conflicto armado interno por el cual atraviesa el país, razón por la cual es 
importante analizar el fenómeno y los derechos que surgen como contraposición a las obligaciones que tiene el Estado en materia de protección y reparación integral de perjuicios.

En términos generales se puede entender el desplazamiento como el traslado involuntario de las personas, asociado a diferentes fenómenos como la violencia, conflicto armado o desastres naturales. Como consecuencia del desplazamiento se presenta para quien lo sufre, cambios de los lugares de habitación, al igual que de sus actividades económicas y rutinarias (Defensoría del Pueblo, 2004). En ese sentido, no se trata sólo de un problema de movilización de un lugar a otro, se trata del rompimiento de sus relaciones individuales, familiares, comunitarias y el desarraigo de su estilo de vida.

Dentro de éste contexto, el presente artículo se enfocará en el desplazamiento interno, sea de forma masiva, individual o familiar, originado por la violencia, en tanto que es una realidad nacional que muchos colombianos han huido de su lugar de origen o de donde tenían fijada su residencia habitual, con el fin de evitar las consecuencias del conflicto armado, en busca de condiciones mínimas de seguridad para custodiar su vida e integridad personal y las de sus familias. Éste tema se abordará frente a la obligación de protección en cabeza del Estado que parece fortalecerse hoy con la expedición de la Ley 1448 del año 2011, mediante la cual se realiza un intento gubernamental por generar vías de restitución y reparación integral a las víctimas del conflicto, cuya aplicación genera para la sociedad Colombiana toda una serie de expectativas y retos.

\section{CONTEXTO DEL DESPLAZAMIENTO FORZADO INTERNO EN COLOMBIA}

Definir la condición de desplazado es demasiado complejo y se pueden encontrar aportes de varias investigaciones para precisar este estatus, sin embargo para efectos del presente estudio, se partirá de la definición dada por el legislador colombiano, a partir de la cual se le ha reconocido como víctima del conflicto:

"Es desplazado toda persona que se ha visto forzada a migrar dentro del territorio nacional, abandonando su localidad de residencia o actividades económicas habituales, porque su vida, su integridad física, su seguridad o libertad personales han sido vulneradas o se encuentran directamente amenazadas, con ocasión de cualquiera de las siguientes situaciones: Conflicto armado interno, disturbios y tensiones interiores, violencia generalizada, violaciones masivas de los Derechos Humanos, infracciones al Derecho Internacional Humanitario $u$ otras circunstancias emanadas de las situaciones anteriores que puedan alterar o alteren drásticamente el orden público"1.

En éste mismo sentido la Organización de Naciones Unidas se ha referido a los desplazados internos como: "las personas o grupos de personas que se han visto forzadas u obligadas a escapar o huir de su hogar o de su lugar de residencia habitual, en particular como resultado o para evitar los efectos de un conflicto armado, de situaciones de violencia generalizada, de violaciones de los derechos humanos o de catástrofes naturales o provocadas por el ser humano, y que no han cruzado una frontera estatal internacionalmente reconocida (Oficina de Coordinación de Asuntos Humanitarios de la ONU - OCHA, 1998). Este Organismo internacional ha promulgado una serie de principios rectores, que aunque no son vinculantes, tienen la finalidad de promover marcos que orienten la definición de las necesidades y derechos de los desplazados internos y los derechos y obligaciones de los Estados y la comunidad internacional en lo referente a su protección y asistencia.

1 Congreso de la República. LEY 387 DE 1.997. Por la cual se establecen medidas para la prevención del desplazamiento forzado; la atención, protección, consolidación y estabilización socioeconómica de los desplazados internos por la violencia en Colombia. Artículo $1^{\circ}$. 
En este aspecto se puede decir, de acuerdo con Donny Meertens (2006), que el desplazamiento es un evento que marca la experiencia subjetiva, desestabiliza a quien lo vive, provoca desorientación a futuro y deteriora el tejido social, al promover la desconfianza y el miedo hacia el otro. La aparición del desplazamiento forzado hace que el estatus de la persona que lo sufre cambie completamente, colocándolo en una situación de desalojo y desarraigo tanto territorial como de sus costumbres familiares y afectivas, el cual es hoy una realidad de la sociedad colombiana y un problema inocultable, que lleva más de 50 años sin soluciones reales, al punto de reconocer que Colombia se ubica como el país con la mayor crisis humanitaria en América Latina (Falla Ramírez, Chávez Plazas y Molano Beltrán, 2003).

Durante las décadas de 1950 y 1960 el desplazamiento forzado en Colombia provocó un cambio en el ordenamiento regional del país. Este fenómeno comenzó a partir de la conformación de las guerrillas liberales, que surgieron como reacción a la persecución política iniciada por el gobierno conservador entre 1946 y 1953 y al asesinato del candidato liberal Jorge Eliecer Gaitán el 9 de abril de 1948, que dio origen a un periodo largo de violencia política (Defensoría del Pueblo, 2004).

Posteriormente, la economía del narcotráfico marco un hito en el desarrollo del conflicto armado y en la colonización de tierras, imponiendo en muchas partes del país reglas de convivencia ante la ausencia del Estado y provocando un aumento significativo del fenómeno del desplazamiento. Para 1997 se estimaba que 4 millones de hectáreas se encontraban en propiedad de narcotraficantes (Sandoval, 1999), quienes de acuerdo con sus intereses realizaban alianzas con grupos de autodefensas ilegales, para contener a la guerrilla, mientras que en otras zonas, el sistema tributario que la guerrilla imponía a estas actividades le servía para financiarse.

En los últimos diez años la magnitud del desplazamiento forzado ha sido creciente, como también es mucho más amplio su reconocimiento, la adopción de los avances internacionales en el tema y las labores de ONG's colombianas y extranjeras para visualizarlo y pedirle al Estado una acción eficiente para su prevención y atención.

En Colombia las áreas rurales de mayor potencial ya están ocupadas, las demás son áreas donde es difícil adelantar un desarrollo productivo y familiar aceptable, lo que obliga al desplazado a asumir como refugios los barrios de las grandes ciudades. El desplazamiento forzado se origina en las áreas rurales del país y se dirige en una alta proporción hacia las ciudades y las capitales de la mayor parte de los departamentos de Colombia y en la mayoría de los casos se insertan en los sectores sociales con mayores niveles de miseria y de vulnerabilidad de las ciudades.

Numerosos estudios se han realizado para hacer seguimiento al fenómeno del desplazamiento, los cuales demuestran el incremento de las familias desplazadas en los últimos años, por ejemplo, según un reporte de la Conferencia Episcopal de Colombia (Pontin, 2005), para el año 1990 se evidenciaron a nivel nacional un total de 176 familias desplazadas provenientes de la Región de la Orinoquía, incrementado para el año 2004 a un total de 242.565 familias, de las cuales 73.101 pertenecen a la Región Atlántica, que correspondía para esa fecha al $30 \%$ del total de la población desplazada en el país; 46.582 familias en la Región Pacífica y 47.576 familias en la Región Central, cada una de éstas regiones con un $19 \%$ de la población desplazada; 25.121 familias en la Región de la Amazonía con un $10 \%$ y el restante en las regiones de la Orinoquía con 17.320 familias, en Bogotá con 16.246 familias y la región Oriental con 15.821 familias desplazadas ${ }^{2}$. Según éste

2 Las Regiones a que se refiere éste estudio se conformaron así: Atlántica: con los departamentos del Atlántico, Guajira, Magdalena, Cesar, Bolívar, Sucre y Córdoba; Pacífica: Chocó, Valle del Cauca, Cauca y Nariño; Central: Huila, Tolima, Caldas, Quindío, Risaralda, Antioquia; Oriental: Cundinamarca, Boyacá, Santander y Norte de Santander; Bogotá: Bogotá, D.C.; Orinoquia: Meta, 
reporte, los incrementos del desplazamiento por regiones se presentaron de forma directamente proporcional al incremento de la violencia y a los enfrentamientos armados, así como al asentamiento sobre todo de guerrilla y grupos de autodefensas durante los periodos en estudio.

Así mismo, el referido reporte arrojó que para el año 2004 la gran mayoría de las familias desplazadas permanecían dentro de su región, bien en el mismo departamento o en departamentos aledaños; siendo la región Atlántica la de mayor concentración de sus desplazados dentro de los municipios que la conforman y Bogotá, la ciudad que más expulsa hacia otras regiones al $90 \%$ de sus familias desplazadas (Pontin, 2005).

En es así como en el informe presentado por la unidad de Atención Integral al Desplazado UAID, se indicó para el año 2003 una población desplazada por la violencia proveniente principalmente de los departamentos de Tolima, Meta, Antioquia, Caquetá, Cundinamarca, Santander y Chocó, por causa del aumento del conflicto armado interno, siendo la capital del país una de las zonas receptoras de desplazados por excelencia (Falla, et al, 2003).

Ahora bien, los reportes oficiales de la Agencia Presidencial para la Acción social y la Cooperación Internacional (Acción Social, 2012), con corte a septiembre de 2011, indican que para la fecha existían un total de 3'875.987 personas en el Registro Único de Población Desplazada -RUPD ${ }^{3}$, lo cual corresponde a 905,114 hogares de familias colombianas desplazadas, es decir que desde el

Arauca, Casanare y Vichada; Amazonia: Putumayo, Caquetá, Guaviare, Vaupés, Guainía, Amazonas y Fronteras por territorios de fronteras en Venezuela, Panamá y Ecuador. Ibídem.

$3 \quad$ El RUPD fue ordenado por Ley 387 de 1997 y creado y reglamentado por el Decreto 2569 de 2000 . El objetivo del registro es tener la información de la población actualizada, según sus características y especificidades, el cual permite identificar a la población y observar la evolución de su situación en todas las fases de atención por parte de Acción Social y otras entidades del Estado. Utiliza el Sistema de Información de Población Desplazada - SIPOD. año 1990 hasta la fecha se ha incrementado el desplazamiento de forma exorbitante en más de 904 mil familias, sin contar en éstas cifras a aquellas personas que han sufrido desplazamiento, pero no han acudido al registro ni a solicitar ayuda gubernamental.

Como se puede observar, el desplazamiento forzado interno en Colombia constituye uno de los problemas humanitarios más graves generados por el conflicto armado en nuestro país, que atenta directamente contra los derechos fundamentales a la libertad e igualdad ${ }^{4}$, el derecho a circular libremente por el territorio nacional ${ }^{5}$ y el derecho a la propiedad privada ${ }^{6}$, entre otros, reconocidos y protegidos por la norma constitucional, lo cual según el referido informe de la UAID se ha generado por la implementación de estrategias para combatir la insurgencia y controlar la sociedad civil por parte de las fuerzas militares, así como la acción directa o indirecta de actores armados como las guerrillas y los grupos de autodefensa. Entre las razones más frecuentes que promueven los altos porcentajes de desplazamiento aparecen las amenazas, torturas, masacres, desapariciones forzadas, destrucción de viviendas, así como los atentados, homicidios, bombardeos, desalojos, reclutamientos forzosos, secuestros, abusos sexuales y las consecuencias de los operativos antinarcóticos (Falla, et al, 2003).

La gravedad de esta situación llevó a la expedición de la ley 387 de 1997, por la cual se buscó adoptar medidas para la prevención del desplazamiento forzado y la atención y protección de los desplazados, consagrando como principales derechos de las personas en dicha situación: el regreso a su lugar de origen, la posibilidad de recibir ayuda internacional, el derecho a no ser discriminado por su condición social de desplazado, su libertad de movimiento sin restricciones, entre otros.

\footnotetext{
4 Constitución Política de Colombia. artículo 13

5 Ibid, articulo 24.

6 Ibid, articulo 58
} 
Posteriormente se expiden una serie de normas que reglamentan la ley 387 de 1997, dentro de las cuales se resaltan el Decreto 290 de 1999, mediante el cual se crearon medidas tendientes a facilitar la inscripción en el Registro Civil de Nacimiento y expedición de documentos de identificación de las personas desplazadas por la violencia ocasionada por el conflicto armado interno; el Decreto 2569 del 12 de diciembre de 2000, por el cual se reglamenta las funciones de la Red de Solidaridad Social como entidad coordinadora del Sistema Nacional de Información y Atención Integral a la Población Desplazada por la violencia; el Decreto 2007 de 2001 sobre atención a la población rural desplazada por la violencia, en el marco del retorno voluntario a su lugar de origen o de su reasentamiento en otro lugar y el Decreto 250 de 2005, mediante el cual se expidió el Plan Nacional para la Atención Integral a la Población Desplazada por la Violencia.

Con el Sistema Nacional de Atención Integral a la Población Desplazada - SNAIPD ${ }^{7}$, el gobierno impulsó una serie de políticas en materia de atención a desplazados y aumentó sustancialmente el presupuesto destinado para tal fin, teniendo como objetivos principales el

7 Creado por el Congreso Nacional mediante la Ley 387 de 1997. Está integrado por 27 Entidades: Agencia Presidencial para la Acción Social y la Cooperación Internacional, Vicepresidencia de la República PDDHH Y DIH, Ministerio de Ambiente, Vivienda y Desarrollo Territorial, Ministerio de Comercio, Industria y Turismo,Ministerio de Educación Nacional, Ministerio del Interior y de Justicia, Ministerio de Hacienda y Crédito Público, Ministerio de Defensa Nacional, Ministerio de Agricultura Desarrollo Rural, Ministerio de Comunicaciones, Departamento Nacional de Planeación, Defensoría del Pueblo, Servicio Educativo Nacional - Sena, Fonvivienda, Comisión Nacional de Televisión, Instituto Colombiano de Bienestar Familiar, Banco Agrario, Instituto Colombiano para el Desarrollo Rural - Incoder, Banco de Comercio Exterior de Colombia - Bancoldex, Consejería Presidencial para la Equidad de la Mujer, Comisión Nacional de Reparación y Reconciliación, Registraduría Nacional del Estado Civil, Instituto Nacional Medicina Legal y Ciencias Forenses, Superintendencia de Notariado y Registrado, Fiscalía General de la Nación, Finagro. atender a la población desplazada en el marco del retorno voluntario y para que ésta lograra su reincorporación a la sociedad colombiana, neutralizar los factores generadores de violencia a través de la protección de los derechos humanos y derecho internacional humanitario, integrar los esfuerzos públicos y privados para prevenir la exteriorización de riesgos frente a la población desplazada y garantizar un manejo eficiente de los recursos para velar con eficacia las situaciones que se presentaban a esta población.

Sin embargo, con relación a la efectividad de éstas políticas en materia de desplazamiento, el tratadista Fernando Medellín (2000) considera que la estructura del SNAIPD era inoperante en el tema de la prevención del desplazamiento, porque no tenía el nivel de control necesario, ni la capacidad para anticipar las acciones de los grupos armados; en sus palabras, la efectividad de las estrategias de prevención depende del trabajo de un equipo de funcionarios de alto nivel, formado y entrenado regularmente en el manejo de crisis de seguridad nacional, con un enfoque integral de evaluación $y$ análisis de implicaciones de decisiones y con una coordinación que dependa directamente del Presidente de la República. Según el referido autor, este Sistema es complementario pero marginal dentro de una estructura eficaz de prevención.

Años más tarde, ante la falta de ejecución efectiva de dichas medidas, la Corte Constitucional declaró "un estado de cosas inconstitucional", en el reconocido fallo T-025 de 2004, ordenando a las autoridades gubernamentales la reformulación de políticas públicas, en pro de la protección y atención de la población desplazada en Colombia, que considera uno de los sectores en estado de vulnerabilidad extrema y a quienes se debe garantizar la igualdad material y la protección efectiva de sus derechos.

La Corte Constitucional reconoce en este fallo, la condición de víctima de los desplazados y recalca que por lo menos 17 derechos fundamentales son violados por el desplazamiento forzado. Por ello ordena, dada su condición de debilidad manifiesta, se les reconozca y garantice el derecho 
a la vida en condiciones dignas, la integridad física, psicológica y moral, el derecho a la familia y a la unidad familiar, el mínimo vital y el derecho al retorno, en aquellos casos en que se quiera de manera voluntaria, enfatizando qué si los desplazados desean retornar no debe impedírseles $y$ deben ser informados por las autoridades en aquellos casos de existencia de circunstancias de orden público que pongan en riesgo su seguridad, para que tomen la decisión de hacerlo o no.

En otro de sus fallos, la Corte Constitucional ${ }^{8}$ definió los derechos que se derivan de la condición de desplazado y afirmó que el Estado, siendo consecuente con su naturaleza de Estado Social de Derecho, tiene la obligación de brindar atención a los desplazados para que acaben para ellos las privaciones del goce de los derechos fundamentales, generando el derecho a ser atendidos prontamente y en condiciones de dignidad. La Corte resalta que el derecho a la reparación conlleva una recuperación efectiva de los bienes abandonados forzosamente o su equivalente y la obligación que tienen las autoridades competentes de asistir a los desplazados que hayan regresado o se hayan reasentado en otro lugar, para la recuperación, en la medida que sea posible, de sus propiedades o posesiones ${ }^{9}$.

A través de sus decisiones la Corte como máxima intérprete de la Constitución en Colombia, puso en consideración del Gobierno algunos puntos importantes para rediseñar las políticas existentes en materia de desplazamiento, dentro de los cuales se resaltan: I. El diseño de un mecanismo excepcional y expedito para resolver las reclamaciones sobre restitución de

8 Corte Constitucional, sentencia T- 327 de 2001

9 Sobre el tema del desplazamiento forzado la Corte Constitucional se ha pronunciado en reiteradas sentencias, de las cuales se destacan: T- 227 de 1997, SU-1150-2000, T-1635-2000, T-327-2001, T-1346-2001, T-098-2002, T-215-2002， C-232-2002， T-268-2003， T-602-2003, T-721-2003， T-985-2003， T-078-2004， T-770-2004, T-813-2004, T-1094-2004, T-097-2005, T-175-2005, T-312-2005, T-882-2005, T-1076-2005, T-086-2006, T- 585 de 2006. predios; II. La definición de presunciones de ilegalidad de las transacciones realizadas sobre los predios despojados e inversión de la carga de la prueba; III. El enfoque de derechos como criterio orientador de las políticas públicas y el respeto del enfoque diferencial y IV. La protección de territorios colectivos de comunidades indígenas y afrocolombianas. (Ministerio de Agricultura y Desarrollo Rural, Departamento Nacional de Planeación, Ministerio del Interior y de Justicia y Acción Social, 2011)

\section{ENFOQUE NORMATIVO DE LA REPARACIÓN INTEGRAL EN EL DESPLAZAMIENTO}

Con la expedición de la Ley 975 de 2005, se dictaron medidas tendientes a la desmovilización de los grupos armados al margen de la Ley como estrategias en busca de la finalización del conflicto armado colombiano. Uno de los derechos que a través de ésta ley se reconoció, fue precisamente la reparación integral a las víctimas ${ }^{10} y$ dentro de ésta, la restitución efectiva de sus tierras, creándose la Comisión Nacional de Reparación y Reconciliación - CNRR, quienes además tenían a su cargo la creación de un programa de restitución de bienes. Tal como lo resaltan en un reciente estudio los académicos Uprimny Yepes y Camilo Sánchez (2010), el documento preparado por la CNRR, recogía los Principios Deng sobre desplazamiento forzado y los principios internacionales relativos a la restitución de viviendas y patrimonio de los refugiados y la población desplazada, conocidos como los Principios Pinheiro, sin embargo aunque no alcanzó a consolidarse en la práctica, constituye un buen fundamento de las políticas recientes en materia de desplazamiento.

Uno de los problemas que presentó ésta Ley en lo relativo a la restitución de tierras, radicó en que los bienes que dispuso como fuente principal para la reparación, no han sido entregados en su totalidad por los victimarios, teniendo en cuenta

10 Ley 975 de 2005. Artículo 8 
que en la mayoría de los casos están ligado a las confesiones y entregas voluntarias que hagan los reinsertados, por cuanto en la mayoría de estos casos las tierras no aparecen a su nombre, sino bajo la titularidad de terceros testaferros.

Por otra parte, es importante resaltar el trabajo de la Mesa Interinstitucional de Tierras (MIT), cuyos documentos buscaron estrategias integrales de reparación, planteando cinco ejes centrales: restitución, prevención, protección, mecanismos transicionales de reparación a víctimas tenedores y formalización y dos ejes transversales correspondientes a sistemas de información y adecuación de la capacidad institucional. (Mesa Interinstitucional de Tierras, 2009)

La obligación del Estado en materia de reparación integral a los desplazados víctimas del conflicto, encuentra también su justificación en el Derecho Internacional Humanitario que protege a la población no combatiente que puede verse afectada por un conflicto interno, mediante la aplicación del protocolo II de 1977 adicional a los convenios de Ginebra y el artículo 17 de la Declaración Universal de Derechos Humanos, que prohíbe expresamente el desplazamiento de la población civil por razones de un conflicto armado.

La normatividad internacional y las normas tanto constitucionales, como legales referidas anteriormente, conforman un cuerpo jurídico básico en el tema del reconocimiento y protección de la población en situación de desplazamiento. Sin embargo, no obstante estos derechos consagrados en la Constitución y reafirmados por la Corte, hasta la fecha no habían tenido medidas efectivas por parte de las autoridades para materializar una verdadera reparación integral.

Ahora bien, en cumplimiento del deber estatal de protección a los desplazados, el actual Gobierno presentó el 14 de septiembre de 2010 el Proyecto de Ley 085 de 2010 ante la Cámara de Representantes, con el fin de establecer normas transicionales para la restitución de tierras, regulando el derecho a la restitución, el procedimiento de restitución y protección de derechos de terceros, la Unidad
Administrativa de Gestión de Restitución de Tierras Despojadas y otras disposiciones sobre la materia. Dicho proyecto fue acumulado con el proyecto de Ley 107 de 2010 sobre reparación a las víctimas del conflicto armado en Colombia, en razón a que éste último incluía un capítulo sobre la restitución de tierras ${ }^{11}$.

En la exposición de motivos se establecieron como objetivos de éstas iniciativas: instituir una política de Estado de asistencia, atención, protección y reparación a las víctimas de violaciones manifiestas a las normas internacionales de Derechos Humanos o infracciones al Derecho Internacional Humanitario $^{12}$. Se buscaba con ello, implementar diferentes mecanismos de reparación integral a las víctimas buscando un enfoque diferencial, acceso a la justicia y conocimiento de la verdad, como herramientas vitales que permitieran el logro de la paz y la reconciliación nacional en Colombia. El mismo Gobierno reconoce en éste documento, que las rutas que se habían implementado para la solución al problema había sido impedido, en la mayoría de los casos por la yuxtaposición de procesos institucionales desarticulados o sin la debida robustez y coordinación de los entes del Estado para satisfacer los derechos de las víctimas, por lo cual se pretendió crear una normatividad con efecto integrador de los distintos avances logrados en la materia y con la fuerza vinculante de la Ley (Cámara de Representantes, 2010)

La reparación integral a la que se refiere éste intento gubernamental, implica que todas las víctimas de violaciones graves a los derechos humanos deben recibir una reparación plena, o al menos proporcional a la gravedad de la

11 Artículo 151. Ley 5 de 1992. Acumulación de Proyectos. Cuando a una Comisión llegare un proyecto de ley que se refiera al mismo tema de un proyecto que esté en trámite, el Presidente lo remitirá, con la debida fundamentación, al ponente inicial para que proceda a su acumulación, si no ha sido aún presentado el informe respectivo. Sólo podrán acumularse los proyectos en primer debate.

12 Exposición de Motivos - versión del 13 de septiembre de 2010 del Proyecto de Ley preparado por el Gobierno Nacional para ser radicado en Cámara de Representantes. 
violación y al daño sufrido, de tal forma que el Estado debe hacer todos los esfuerzos posibles para borrar los efectos del crimen y deshacer el daño causado, con el fin de restituir a la víctima a la situación en la que se encontraba con anterioridad (Uprimny 2010).

El referido proyecto surtió el trámite legislativo correspondiente y el 10 de junio de 2011 se convirtió en la Ley 1448 "Por la cual se dictan medidas de atención, asistencia y reparación integral a las víctimas del conflicto armado interno y se dictan otras disposiciones". Para el caso del desplazamiento forzado, la norma consagra tres tipos de medidas de asistencia y atención: atención inmediata, atención humanitaria de emergencia y atención humanitaria de transición, que se deben aplicar por parte de las autoridades competentes, previa valoración de la condición de vulnerabilidad de la víctima del desplazamiento.

La atención inmediata se presta para las víctimas de desplazamiento a quienes se reconozca un alto nivel de vulnerabilidad y que requieran albergue temporal y asistencia alimentaria, desde el momento en que se hace la declaración de víctima ante el Ministerio Público y hasta que es inscrito en el Registro Único de Población Desplazada, que seguirá en funcionamiento hasta que opere el Registro Único de Víctimas. Ésta primera atención humanitaria debe ser prestada de forma preferente por parte del municipio a donde llega la víctima, siempre y cuando el hecho generador del desplazamiento no supere los 3 meses de ocurrido ${ }^{13}$.

La atención de emergencia para los desplazados una vez hayan quedado inscritos en el Registro Único de Población Desplazada, se presta por parte de la Agencia Presidencial para la Acción Social, mientras que entra a operar la Unidad Administrativa Especial para la Atención y Reparación Integral a las Víctimas, de acuerdo al grado de necesidad y

13 Congreso de la República. Ley 1448 de 2011. Titulo III, Capítulo III, artículo 63. urgencia respecto de su subsistencia mínima, como por ejemplo el alimento ${ }^{14}$.

Por último, se refiere a la atención humanitaria de transición, la cual va encaminada a prestar ayuda a los desplazados inscritos en el Registro Único, que sin tener el grado de urgencia o gravedad, aún no cuentan con los recursos necesarios para asumir su subsistencia mínima, aquí se incluyen los planes de apoyo en alimentación adelantados por el ICBF para los hogares de desplazados, las medidas de alojamiento temporal y los programas de empleo dirigidos hacia éstas víctimas ${ }^{15}$.

Con relación al derecho que tienen las víctimas del desplazamiento a retornar a sus lugares de origen o a ser reubicados siempre que existan condiciones de seguridad favorables, la ley consagra la obligación delEstado de diseñar esquemas especiales de acompañamiento y atención integral, en lo relacionado con sus derechos mínimos de identificación, salud, educación, alimentación y reunificación familiar, vivienda digna y orientación ocupacional, a cargo de las entidades que conforman el Sistema Nacional de Atención y Reparación ${ }^{16}$, y se remite a la política pública de prevención, protección y atención integral para las víctimas del desplazamiento forzado, consagrado en la Ley 387 de 1997.

Se establece la obligación de evaluar cada dos años las condiciones de vulnerabilidad y debilidad manifiesta ocasionadas por el hecho del desplazamiento, a través de políticas de seguimiento a los hogares y en caso de encontrar superada dicha situación, por cuanto la víctima ha logrado el goce efectivo de sus derechos, se procederá a hacer el registro en el RUV, sin embargo, se continúa reconociendo su calidad de víctima para que pueda exigir los demás derechos que se desprenden de tal situación, por ejemplo a la verdad y a la no repetición.

\footnotetext{
14 Ibidem. Artículo 64.

15 Ibidem. Artículo 65.

16 Ibídem. Artículo 65.
} 
El principal derecho que tiene la víctima del desplazamiento forzado o del despojo ${ }^{17}$, es la restitución tanto jurídica como material del mismo inmueble que tenía antes de ser despojado o desplazado, bien en su calidad de propietario, es decir con título de dominio inscrito, o en calidad de poseedor del inmueble. Subsidiariamente en aquellos casos en que sea imposible la restitución, por situaciones de riesgo para la vida e integridad de la víctima, tendrá derecho a que se le consulte para su reubicación en otro inmueble equivalente en cuanto a valor y características y como última disposición corresponde la compensación en dinero, cuando no sean posibles las anteriores medidas de restitución.

Lo que se busca con esto es, en los términos de la misma ley, el restablecimiento progresivo del proyecto de vida de las víctimas dentro del marco de los principios de prevención de nuevos actos de despojo o desplazamiento, la protección jurídica de sus derechos de dominio o posesión, la protección física e la integridad de las víctimas y participación activa de las mismas en dicho proceso.

Para la reclamación de éste derecho a la restitución de las tierras, se limita a los hechos de despojo o desplazamiento ocurridos a partir del 1 de enero de 1991, lo cual ha generado entre las mismas victimas y la opinión publica un amplio debate y controversia por cuanto se excluyeron las víctimas de los mismos hechos ocurridos con anterioridad, sin tener en cuenta que durante la década de los años ochenta y principio de los noventa la

17 En los términos del artículo 74 de la Ley 1448, el despojo se presenta cuando se ha privado arbitrariamente a una persona de su propiedad, posesión u ocupación, ya sea de hecho, mediante negocio jurídico, acto administrativo, sentencia, o mediante la comisión de delitos asociados a la situación de violencia. Mientras que el abandono forzado se vincula a la situación de violencia que obliga al desplazamiento de las víctimas quienes abandonan sus inmuebles y por lo tanto pierden su tenencia y administración. situación de violencia en Colombia era de unas magnitudes superiores por el fortalecimiento del narcotráfico y la guerra entre los capos, lo cual generó tanto despojos violentos de grandes cantidades de terreno, como altos índices de desplazamiento al interior del país.

Esta norma contempla la creación de un registro de tierras despojadas y abandonadas forzosamente, como instrumento para la restitución, a cargo de la Unidad Administrativa Especial de Gestión de Restitución de Tierras ${ }^{18}$, a través del cual se llevará el registro de los inmuebles y las familias que ejercieron propiedad o posesión, de oficio o a petición de parte por los interesados y cuya inscripción será requisito de procedibilidad para iniciar la acción de restitución. Previamente a realizar la referida inscripción, el funcionario debe notificar a los propietarios y poseedores actuales del predio para darles la posibilidad de presentar las pruebas de sus derechos, para determinar la buena o mala fe de los ocupantes ${ }^{19}$.

Igualmente consagra un procedimiento especial para que pueda operar la restitución, iniciando con una solicitud de restitución ante el Juez competente por parte del despojado o desplazado, directamente o a través de abogado, o por varias víctimas de forma colectiva, cuando exista

18 Para facilitar y agilizar el trabajo de ésta Unidad Especial de Restitución se le permite el acceso a las bases de datos sobre víctimas y tierras que lleva el Instituto Geográfico Agustin Codazzi, las oficinas de Catastro a nivel nacional, las notarias, la Superintendencia de Notariado y Registro, el Incoder, las Oficinas de Registro de Instrumentos Públicos en todo el país y demás entidades públicas que requiera, igualmente debe compartir información con la Unidad Administrativa Especial para la Atención y Reparación Integral a las Víctimas, en lo posible en tiempo real a través de la estrategia de Gobierno en Línea, o en los demás casos con términos máximos de 10 días para entregar la información requerida.

19 Ibídem. Artículo 76. 
uniformidad en la vecindad de los bienes y el tiempo y causa del desplazamiento o por la Unidad Administrativa Especial de Restitución de Tierras, de oficio o por solicitud directa, que la víctima realice al funcionario de ésta entidad para que lo represente.

Para tramitar éste proceso se crean Jueces y Magistrados con competencia especial para la restitución de tierras, de tal forma que conocen en única instancia los Jueces Civiles del Circuito especializados cuando durante el proceso no se reconocen opositores y de lo contrario tramitan el proceso antes del Fallo y lo remiten a la sala civil especializada del Tribunal Superior del Distrito Judicial, para que profiera sentencia y conozca de la consulta de las sentencias de los Jueces del Circuito cuando no se decretó la restitución a favor del solicitante.

El proceso finaliza con sentencia que de ser favorable, pondrá la titularidad del inmueble a favor del demandante, tal como se observa en el siguiente flujograma que esquematiza el procedimiento:

\section{ORGANIGRAMA DEL PROCEDIMIENTO JUDICIAL DE RESTITUCIÓN DE TIERRAS}

$\begin{aligned} & \text { 1. Presentación de } \\ & \text { solicitud. Demanda }\end{aligned}$
$\begin{aligned} & \text { escrita u oral ante el } \\ & \text { juez (art. } 84 \text { ley 1448) }\end{aligned}$ $\begin{aligned} & \text { 2. Reparto de la solicitud. } \\ & \text { A mas tardar al sig. día hábil. } \\ & \text { Art. } 86 . \text { Tramite diferente en } \\ & \text { consideración al estado de } \\ & \text { vulnerabilidad de la victima }\end{aligned}$

SOLICITUD

\section{Publicación de} admisión de solicitud. Diario de amplia circulación Nacional para que 3ros hagan valer sus derechos.

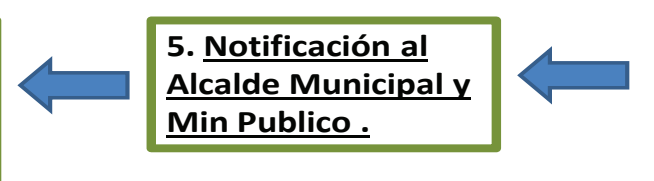
Alcalde Municipal Min Publico.
3. Admisión de demanda. A mas tardar al siguiente día hábil. Art. 86. Tramite diferente en consideración al estado de vulnerabilidad de la victima

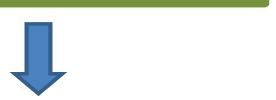

\section{Medidas cautelares.} Se pueden solicitar en cualquier estado del proceso para prevenir un daño inminente o para cesar el daño causado al inmueble.

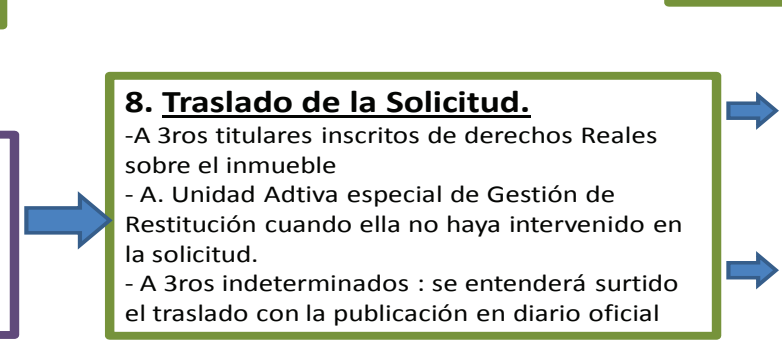

\section{Inscripción de la solicitud en la Oficina de Registro de Inst. Públicos.}

\subsection{No} comparecen. Nombramiento de Representante Judicial. 5 días

$8.2 \mathrm{Si}$ comparecen.

Fuente: Autor*

Con el registro del inicio del proceso el inmueble sale provisionalmente del comercio y se suspenden los procesos declarativos de derechos reales sobre el predio, procesos sucesorios, divisorios, de deslinde y amojonamiento, posesorios, de restitución de tenencia, declaraciones de pertenencia, embargos y otros en relación con el predio objeto del proceso. No suspende procesos de expropiación. 


\section{PERIODO PROBATORIO}

\section{Practica de Pruebas. \\ - 30 días para practica de pruebas decretadas que se consideren pertinentes $\mathrm{y}$ conducentes. $* * *$ \\ SENTENCIA}

\section{Sentencia.}

- Constituye titulo de propiedad o posesión suficiente. Art. 91
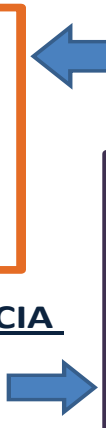

OPOSICIONES

10. Admisión de oposiciones.

-Si son pertinentes.

12. 1. Se debe pronunciar sobre la propiedad, posesión del bien u ocupación del baldío objeto de la demanda.

-Decretara las compensaciones, en relación con las mejoras, para los opositores de buena fe exenta de culpa

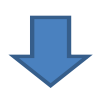

14. Recursos.

- Procede

Fuente: Autor

\section{Presentación}

\section{oposiciones.}

-15 días hábiles. Por escrito.

- 3ros bajo gravedad de juramento.

- Unidad Adtiva especial de

Gestión de Restitución: anexar

todas las pruebas.

\section{Inscripción de la} sentencia en Oficina de Registro de Instrumentos

\section{Públicos.}

-Cancelación de otros gravámenes

limitaciones de dominio,

arrendamientos, medidas

cautelares o registros con

posterioridad al despojo

-Inscripción de la declaración de

pertenencia o adjudicación de

baldíos a favor del solicitante.

* La Ley estableció que el bien se deberá titular a nombre de los dos cónyuges o compañeros permanentes que cohabitaban al momento del desplazamiento o despojo, así al momento de la sentencia se encuentren separados.

Durante éste procedimiento se consagraron varias presunciones en favor de las víctimas, por ejemplo, la presunción de derecho ${ }^{20}$ de ausencia de consentimiento o causa ilícita en los negocios jurídicos de transferencia de derechos reales sobre los inmuebles inscritos en el Registro de Tierras despojadas, celebrados entre la víctima o sus familiares mayores y personas que hayan sido condenadas por pertenencia, colaboración o financiación de grupos armados ilegales o por narcotráfico y delitos conexos.

Igualmente se consagra una presunción legal ${ }^{21}$ de ausencia de consentimiento o causa ilícita en los negocios jurídicos de transferencia de derechos reales, cuando por la época y la zona hayan ocurrido actos de violencia generalizados, desplazamientos masivos, graves violaciones de derechos humanos o si se hubiere solicitado sobre

20 Jurídicamente significa que no admite prueba en contra.

21 Este tipo de presunción si puede ser desvirtuada con pruebas que demuestren lo contrario. dichos inmuebles las medidas de protección que consagra la ley 387 de 1997. Del mismo modo se aplica esta presunción si por la época de celebración del negocio, se hubiera producido el fenómeno de concentración de la propiedad sobre varios terrenos vecinos en cabeza de una o más personas, se hubiere alterado significativamente el uso de la tierra, se hubiere vendido por menos de la mitad del precio real o síse celebró con personas extraditadas por narcotráfico o delitos conexos.

Ésta presunción se aplica por ejemplo cuando en los terrenos se verifica el cambio de cultivos agrícolas de consumo por monocultivos, ganadería extensiva o minería industrial.

El efecto de aplicar las referidas presunciones es la inexistencia del acto jurídico y la nulidad absoluta de todos los actos que se hubieren celebrado con posterioridad. Así mismo, cuando dentro del proceso se prueba el hecho del despojo o del abandono forzado del inmueble por parte de la víctima, se presumen nulos los actos administrativos que hubieren sido expedidos con posterioridad al 
hecho ilícito y con los cuales se hubiera legalizado una situación jurídica contra los derechos de la víctima, igualmente se aplica para las sentencias judiciales que se hubieran dictado sobre dichos predios para declarar la propiedad en favor de un tercero, presumiendo que la víctima no pudo, por causa de la violencia, acudir al proceso a hacer uso de sus derechos de defensa y contradicción, por lo cual se permite al Juez o Magistrado revocar dichas decisiones judiciales.

Adicionado a lo anterior hay que tener en cuenta el problema probatorio de demostrar la titularidad del derecho real de dominio o el hecho de la posesión en cabeza del desplazado y su contraposición con posesiones de terceros $\mathrm{u}$ otros titulares del dominio posteriores a la ocurrencia del desplazamiento, quienes podrán presentar oposiciones dentro del proceso de restitución. Al respecto, se consagró el principio de inversión de la carga de la prueba a favor de las víctimas, a quienes les basta presentar la prueba sumaria de la propiedad o posesión y su reconocimiento como desplazados o despojados, para trasladar la prueba al demandado o a quien haga oposición.

Ahora bien, como se puede observar en el flujograma, se consagran términos perentorios tanto para la práctica de pruebas, decisión de oposiciones y fallo con la consecuencia de considerar como falta gravísima su incumplimiento, ante lo cual es importante cuestionarse sobre ¿cuántas solicitudes se van a presentar por parte de las víctimas? y frente a ello, ¿cuántos jueces y magistrados especiales van a nombrar para poder cumplir estos términos?, y si cla estructura administrativa y presupuestal que se tiene proyectada, es suficiente para cumplir éste propósito?.

Al respecto, en la propuesta sobre la Jurisdicción para la Restitución de Tierras, que ha venido trabajando la Sala Administrativa del Consejo Superior de la Judicatura (2011), se calcula que se recibirán cerca de 300.000 casos de restitución de tierras durante los próximos 10 años de vigencia de la Ley, frente a la necesidad de restituir alrededor de 360.000 predios en toda Colombia, según cifras del Registro Único de Población Desplazada con corte al 31 de julio de 2011. Adicionalmente según tendencia del RUPTA, se espera restituir alrededor de 270.000 predios a propietarios y poseedores, se compensarán a 30.000 campesinos que demuestren buena fé y se presentarán 60.000 casos de tenedores y predios en zonas no adjudicables.

Dentro de éste marco, se remitió para su estudio ante el Ministerio de Agricultura y Desarrollo Rural, la propuesta de creación para los próximos 3 años de aproximadamente 134 Jueces Civiles del Circuito Especializados en Restitución de Tierras y 60 Magistrados Especializados, de forma gradual así; 22 jueces y 15 magistrados durante el año 2012; 69 jueces y 30 magistrados en el 2013 y 134 jueces y 60 magistrados para el año 2014, estando todavía pendientes por definir el número de Jueces del Circuito Itinerantes, que se crearán con el fin de apoyar en el recaudo y práctica de pruebas.

En materia presupuestal, la creación de éstos despachos incluyendo el personal de apoyo, tales como secretarios, oficiales mayores, escribientes, citadores y auxiliares judiciales en sistemas, para el caso de los Juzgados y un auxiliar judicial más un abogado asesor para los Tribunales, superarían la suma de $\$ 71.600$ millones de pesos, para un total aproximado de 1.151 cargos. Para comenzar la creación de ésta jurisdicción especial, en el año 2011 , se dispuso de recursos por un monto de 4.200 millones de pesos, que muy seguramente tendrá que aumentarse progresivamente para las siguientes vigencias fiscales.

Con respecto a la ubicación territorial donde se crearán los primeros Jueces y Magistrados, en la propuesta se resaltan las zonas que según fuentes oficiales, presentan una mayor densidad de casos de desplazamiento y despojo de predios, por lo que se proyecta ubicar Juzgados durante el 2012 en las zonas de Urabá, Bajo Cauca, Magdalena Medio, Valle del Cauca, Montes de María, Cartagena, Norte de Santander, Tolima, Oriente Antioqueño, Putumayo, Montería, Nariño, Cauca, Chocó, Norte 
del Magdalena, Montes de María sucreño, Cesar, Meta y Bogotá y para los Tribunales Especializados se proyectan en zonas centrales como Cartagena, Medellín, Bogotá, Cúcuta y Cali.

Actualmente se adelantan cursos de capacitación para los funcionarios judiciales sobre la implementación de la Ley de restitución y formalización de tierras con el fin de comprender el nuevo procedimiento y las figuras jurídicas transicionales que trajo consigo; manejo de la prueba, presunciones a favor de las víctimas, titulación de la propiedad, medidas de compensación, propiedad colectiva de grupos étnicos, derechos humanos, entre otros. La adecuada formación de los funcionarios judiciales a cargo de la aplicación de la Ley es vital dentro del proceso de una reparación efectiva.

En cuanto a la aplicación de éstas nuevas políticas, el profesor Rodrigo Uprimny (2010), defiende un modelo de restitución en perspectiva de reforma agraria, donde se busquen mecanismos que no sean puramente correctivos sino que tengan también vocación redistributiva, para lograr así una mayor inclusión social y económica de gran parte de la población rural, a través de lo que denomina democratización de la propiedad agraria que no es otra cosa que redistribuir la propiedad acompañada de medidas de desarrollo económico rural, teniendo en cuenta que la gran mayoría de desplazados en Colombia son personas pobres, que si se limita la reparación a la simple restitución a su estado anterior, sería devolverlos a un estado de miseria.

Las políticas de restitución de tierras deben ir acompañadas de un esfuerzo institucional mayor, que amplíe el ámbito de la reparación a otros campos adicionales a la mera relación persona - tierra, a través de la devolución y titulación de predios y propiciar el desarrollo integral del proyecto de vida de las víctimas, en lo familiar, económico y social, sin olvidar que la reparación también implica el derecho a la no repetición y a obtener una protección efectiva por parte del Estado, lo cual no se dará dentro de un contexto de conflicto armado, con intentos decaídos de acuerdos de paz.

Sobre esta nueva iniciativa legislativa Norbert Wühler, Jefe del Programa de Reparación a nivel mundial de la Organización Internacional para las Migraciones, expresó que es una apuesta que implica un esfuerzo de todo el Estado colombiano, para que las víctimas recuperen el modelo de vida que tenían antes de ser victimizadas y representa el programa más ambicioso e integral de reparación que se haya visto en el Mundo entero ${ }^{22}$.

\section{CONCLUSIONES}

Como se puede observar, la problemática del desplazamiento pese a estar ampliamente regulada, subsiste en la práctica, con problemas en cuanto al desarrollo y mecanismos que utiliza el Gobierno nacional para solucionar efectivamente la crisis social que se vive en el país, siendo uno de los retos más complejos que tiene el Estado colombiano el restablecimiento de las tierras a la población desplazada, pero una obligación que no puede eludir.

Con respecto a los problemas que habían presentado las políticas existentes en materia de desplazamiento, la Defensoría del Pueblo indicó que a la fecha no existía todavía un marco normativo especial que regulara los procedimientos, las responsabilidades y las sanciones de los funcionarios del Estado encargados de la atención a la población civil desplazada, que no cumplen su función. Igualmente en cuanto a la reparación de los derechos violados tampoco existía una norma clara y que pudiera ser verdaderamente aplicable en contra de los autores materiales e intelectuales del desplazamiento forzado, para obligarlos a restituir las tierras y reparar integralmente sus víctimas (Defensoría del Pueblo, 2004), razón por la cual la expedición de la Ley 1448 genera expectativas respecto de

22 Informe de Ponencia para segundo debate. Proyecto de Ley Número 107 de 2010 (ACUM. PL 85/10 Cámara). 30 de noviembre de 2010. 
su aplicación efectiva, al punto que la opinión pública considera que "hoy, hay más esperanzas que certezas. Su funcionamiento dependerá del impulso del Gobierno tanto en lo económico y lo institucional y de las exigencias de la sociedad civil" (Ámbito Jurídico, 2011).

La expedición de la denominada Ley de Víctimas implica un esfuerzo de todos los entes del Estado: Legislativo, Ejecutivo y Judicial, por buscar herramientas que lleven a la práctica los principios constitucionales $e$ internacionales suscritos $y$ ratificados por Colombia en materia de protección a la población civil dentro del contexto del conflicto armado, lo cual conlleva replantear otras políticas en materia de desarrollo social y de apoyo a la producción agraria, políticas educativas para las personas mas desfavorecidas y destinar presupuesto con miras a su efectividad.

Los retos son bastantes; por un lado fortalecer los sistemas de información, a través de los registros de víctimas y de tierras, que han sido considerados por la Ley como requisito de procedibilidad para acudir a la vía judicial especial, pero que además tienen un componente importante en el seguimiento que el Estado pueda hacer a la veracidad de los hechos denunciados en las solicitudes de reparación. Es importante que los sistemas informáticos se encuentren unificados con datos lo más certeros posibles y que estén a disposición de todas las autoridades que participan en dicho procedimiento.

Igualmente se establecieron medidas de restitución subsidiarias para aquellas victimas a quienes no sea posible hacer la entrega del mismo predio, lo cual implicará esfuerzos del Estado por conseguir tierras productivas que puedan ser objeto de titulación, del mismo modo se requiere un esfuerzo económico bastante importante para la compensación de los terceros opositores que demuestren buena fe en la tenencia de los predios y a quienes la Ley reconoce compensaciones económicas, que deberán ser proporcionales al daño que puedan sufrir.

El esfuerzo económico también se requerirá en la organización de estructuras administrativas para ejecutar lo ordenado por la Ley, tal como se vio, desde la creación de la Unidad de Gestión Integral de la Restitución, una nueva Superintendencia Delegada para la Formalización, Protección y Restitución de Tierras y Despachos judiciales especializados en toda Colombia, hasta la restructuración de entidades existentes pero que requieren fortalecerse para cumplir nuevas funciones.

Queda aún en la agenda gubernamental lo relacionado a las políticas de seguridad a implementarse por parte de las Fuerzas Armadas y de Policía con el propósito de impedir la repetición de los hechos generadores del desplazamiento $y$ en un mediano plazo, propuestas reales de justicia transicional que permitan la finalización del conflicto, para que el derecho a la reparación integral no sea simplemente un derecho consagrado en la Ley como mera ilusión de las víctimas, sino una realidad que materialice la justicia.

\section{BIBLIOGRAFÍA}

Acción social, Subdirección de Atención a Población Desplazada. (s/f). Registro. consultada el 15 de agosto de 2010 en: http:// www.accionsocial.gov.co/contenido/contenido. aspx? catID $=295 \&$ conID $=1953$

Acción Social - Sistema de Información para la Población Desplazada. (s/f) Dinámica del Desplazamiento Forzado en Colombia. En: http:// www.accionsocial.gov.co/estadisticasdesplazados/ DinamicaGeneral.aspx fecha de consulta 23 de marzo de 2012.

ÁMBITO JURÍDICO. (2011, Junio 23). Así quedó la Ley de Victimas. Edición No. 323.

CÁMARA DE REPRESENTANTES. (2010, Septiembre 13). Exposición de Motivos del Proyecto de Ley 107 de 2010.

CÁMARA DE REPRESENTANTES. (2010, Noviembre 30) Informe de Ponencia para segundo debate. Proyecto de Ley Número 107 de 2010 (ACUM. PL 85/10 - Cámara). 
CORTE CONSTITUCIONAL. MP: Manuel José Cepeda Espinosa. ( 2004, Enero 22). Sentencia T-025. Expediente. T- 653010 y acumulados.

CORTE CONSTITUCIONAL COLOMBIANA. MP: Marco Gerardo Monroy Cabra. (2001, Marzo 26). Sentencia T- 327.

CONGRESO DE LA REPÚBLICA DE COLOMBIA. (2001, Julio 18). Ley 387. Por la cual se establecen medidas para la prevención del desplazamiento forzado; la atención, protección, consolidación y estabilización socioeconómica de los desplazados internos por la violencia en Colombia.

CONGRESODELAREPÚBLICADECOLOMBIA. (2005, Julio 25). Ley 975.

CONGRESODELAREPÚBLICADECOLOMBIA. (2011, Junio 10). Ley 1448.

CONSULTORÍAPARALOSDERECHOSHUMANOS YEL DESPLAZAMIENTO - CODHES consultada el 16 de agosto de 2010 en: http://www.codhes. org/index.php?option $=$ com_frontpage\&Itemid $=2$

CONVENCIÓN AMERICANA SOBRE DERECHOS HUMANOS. (1969, Noviembre 22) Suscrita en San José de costa rica el 22 de Noviembre de 1.969 y estrada en vigor en Colombia el 18 de julio de 1.978, por medio de la ley 16 de 1.972.

CONVENIOS DE GINEBRA. (1.949, Agosto 12). Entrado en vigor en Colombia por la ley 171 de 1.994 y sus protocolos adicionales.

DECLARACIÓN UNIVERSAL DE LOS DERECHOS HUMANOS. (1948, Diciembre 10). Adoptada por la Asamblea General de las Naciones Unidas en su resolución 217 A (III).

DEFENSORÍA DEL PUEBLO DE COLOMBIA. (2004). Desplazamiento Forzado en Colombia. Serie Red de Promotores de Derechos Humanos, Bogotá.
DECRETO 290 de 1999. Por el cual se dictan medidas tendientes a facilitar la inscripción en el Registro Civil de Nacimiento y expedición de documentos de identificación de las personas desplazadas por la violencia ocasionada por el conflicto armado interno.

DECRETO REGLAMENTARIO 2569 de 2000 Por el cual se reglamenta parcialmente la ley 387 de 1.997 y se dictan otras disposiciones.

DECRETO 2007 de 2001, Por el cual se reglamenta parcialmente los artículos $7^{\circ}, 17$ y 19 de la Ley 387 de 1997, en lo relativo a la oportuna atención a la población rural desplazada por la violencia, en el marco del retorno voluntario a su lugar de origen o de su reasentamiento en otro lugar y se adoptan medidas tendientes a prevenir esta situación.

DECRETO 250 DE 2005, Por el cual se expide el Plan Nacional para la Atención Integral a la Población Desplazada por la Violencia y se dictan otras Disposiciones.

GAVIRIA BETANCUR, Paula. (2004). Desplazamiento forzado en Colombia. Defensoría del pueblo, red de promotores de Derechos Humanos. Bogotá D.C- Colombia.

MEDELLIN, Fernando. (2000) Los desafíos de la política de resarcimiento de población desplazada por la violencia. Banco mundial. Bogotá.

MEERTENS, Donny. (2006). Reflexiones éticas, metodológicas y conceptuales sobre la investigación en desplazamiento y género. En Investigación y desplazamiento forzado. Bogotá: Ed. Martha Nubia Bello A. Colciencias. Bogotá, Colombia.

MINISTERIO DE AGRICULTURA Y DESARROLLO RURAL, DEPARTAMENTO NACIONAL DE PLANEACIÓN, MINISTERIO DEL INTERIOR Y DE JUSTICIA, ACCIÓN SOCIAL. (2011, Marzo 16). Enfoques y Propuestas de la Política de Tierras para la Población Desplazada. 
OFICINA DEL ALTO COMISIONADO DE LAS NACIONES UNIDAS PARA LOS REFUGIADOS (ACNUR). (2008). Balance de la Política Pública para la Atención Integral al Desplazamiento Forzado en Colombia: Enero 2004 - abril 2007.

OFICINA DE COORDINACIÓN DE ASUNTOS HUMANITARIOS DE LAS NACIONES UNIDAS - OCHA. (1988). Principios Rectores de los Desplazamientos Internos de las Naciones Unidas. E/CN.4/1998/53/Add.2

PROYECTO DE LEY 085 DE 2010 CÁMARA, Por la cual se establecen normas transicionales para la restitución de tierras

PONTIN Maurizio. (2005). Población en situación de desplazamiento en Colombia: un análisis por Regiones. Segundo informe de investigación elaborado para la sección de movilidad humana de la Conferencia Episcopal de Colombia. Editorial Kimpres. 2005.

RAMAJUDICIALDELPODERPÚBLICO, Consejo Superior de la Judicatura, Sala Administrativa, Mg. Nestor Raul Correa Henao. (2011). Propuesta sobre la Jurisdicción para la Restitución de Tierras (cumplimiento a la Ley 1448 de 2011, Bogotá.
Universidad de Caldas. (2007). RESTABLECIMIENTO, REPARACIÓN Y PROCESOS ORGANIZATIVOS DE LA POBLACIÓN EN SITUACIÓNDEDESPLAZAMIENTO. Manizales. Centro Editorial Universidad de Caldas.

SANDOVAL, Marbel. (1999). "Desplazados, una historia son contar." En: Universitas Humanistica No. 47 Pontificia Universidad Javeriana Bogotá.

UPRIMNY YEPES Rodrigo, SÁNCHEZ Camilo. (2010). Los Dilemas de la Restitución de tierras en Colombia. Documentos de Discusión No. 5. De Justicia.

UVA FALLA RAMÍREZ, YURI A. CHÁVEZ PLAZAS y GLADYS MOLANO BELTRÁN DESPLAZAMIENTOFORZADO ENCOLOMBIA. (2003). Análisis documental e informe de investigación en la Unidad de Atención Integral al Desplazado (UAID) - Bogotá. En: Tabula Rasa. Bogotá - Colombia, No.1: 221-236, enerodiciembre de 2003 http://www.revistatabularasa. org/numero uno/Ufalla.pdf

ZULUAGA NIETO, Jaime, (1998). "Tendencias del desplazamiento forzoso en Colombia", memorias del foro "Desplazados Internos en Antioquia", Medellín. 